\title{
EDITORS FOCUS
}

\section{Early Career Investigator}

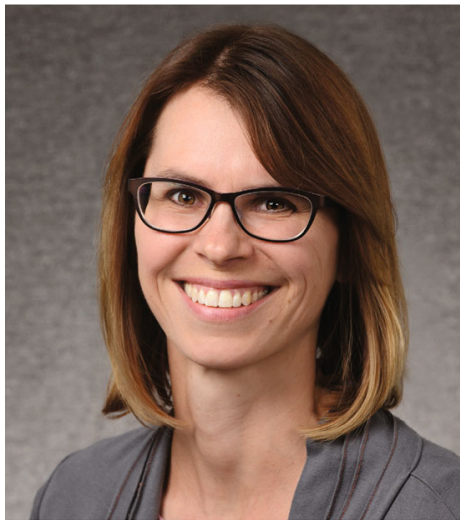

Congratulations to Maggie Stanislawski, August's Early Career Investigator. A native of Colorado, Maggie fell in love first with mathematics, then epidemiology and the microbiome. Her interest in health care began with a stint in the Peace Corps in Tanzania. She started her career at the Veterans Administration, but quickly turned to the study of younger populations. Her advice to early researchers is to take the time and be patient when deciding their future career. In an article in this issue, she and colleagues explain how the gut microbiota is associated with the hepatic fat fraction in adolescents. See pages 148 and 219

\section{Special commentary on immigration policy}

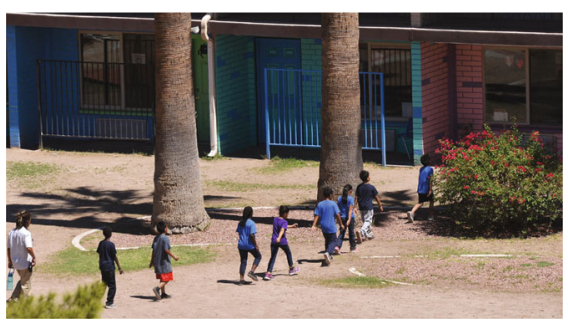

In this policy commentary, the Pediatric Policy Council reviews the scientific evidence that separation of children from their families has serious longterm health consequences and poses questions that the United States-and perhaps all other societies—must address. See page 149

\section{Environmental chemicals and blood pressure}

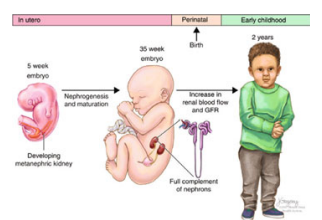

Sanders et al. reviewed 36 articles describing the relationship between environmental pollutant exposure during early life and high blood pressure. They found the strongest association between air pollutants and blood pressure, calling for more studies on nephrotoxicant exposures. See page 165

\section{Exposure to the 9/11 attacks and subsequent behavior and mental health}

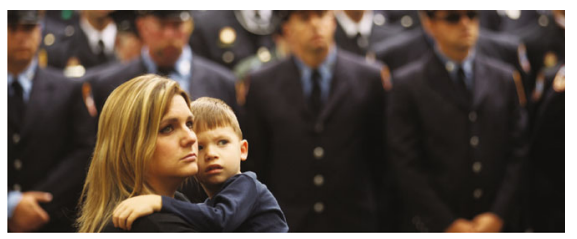

Gargano et al. analyzed the data from World Trade Center Health Registry enrollees who had completed at least one survey as an adolescent (age 11-17 years) and at least one adult survey (age 18 or above). They found a relationship between adolescent behavioral problems related to experiencing the World Trade Center attacks in childhood and adult mental health issues and substance use. The findings indicate the importance of continued monitoring of those exposed to the attack, as well as of early intervention for children exposed to traumatic events. See page 205

\section{IL-6 levels in amniotic and gastric fluid}

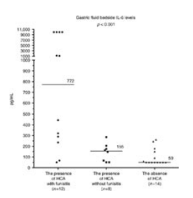

Musilova et al. compared levels of interleukin-6 (IL-6) in amniotic fluid at admission with those in gastric fluid at birth in pregnancies with premature prolonged rupture of membranes. They found a significant increase in IL-6 in women with funisitis and fetal inflammatory response syndrome, which suggests that such changes can serve as a biomarker for these conditions. See page 240

\section{Prediabetes rates in children in Canada}

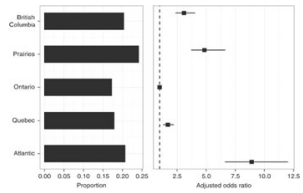

Using the Canadian Health Measures Survey, Rodd et al. extracted hemoglobin A1C as a biomarker for prediabetes and determined independent predictors for 6- to 19year olds. The prevalence of prediabetes in this group was $5.2 \%$ and predicted by race/ ethnicity, physical activity, and parental education. Significant regional variations were noted. See page $\mathbf{2 4 8}$

\section{Esophageal epithelial cells differ in eosinophilic esophagitis}

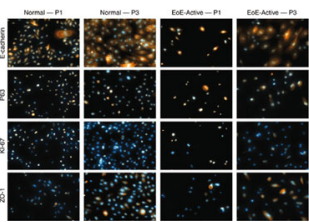

Sayej et al. obtained esophageal epithelial cells from children with eosinophilic esophagitis that was either active or in remission and those with no esophageal inflammation. Cells from active patients had different integrin profiles. When stimulated with antigens, these cells express MHC class II molecules on their surfaces. When cocultured with autologous T cells, they increase secretion of IL-6 and TNF-a. See page 306 